American Journal of Pharmaceutical Education 2019; 83 (3) Article 6584.

\title{
RESEARCH
}

\section{Implementation of an Interprofessional Medication Therapy Management Experience}

\author{
Katherine E. Schussel, BSN, RN, ${ }^{\mathrm{a}}$ Stephanie Forbes, PharmD, ${ }^{\mathrm{a}}$ Ann M. Taylor, MPH, \\ Janet H. Cooley, PharmD ${ }^{b}$ \\ ${ }^{a}$ SinfoníaRx, Tucson, Arizona \\ ${ }^{\mathrm{b}}$ University of Arizona College of Pharmacy, Center for Health Outcomes and Pharmacoeconomic Research, \\ Tucson, Arizona
}

Submitted June 13, 2017; accepted September 20, 2017; published April 2019.

\begin{abstract}
Objective. To measure the impact of an interprofessional experience (IPE) in medication therapy management (MTM) on students' attitudes and skills regarding interprofessional collaboration (IPC). Methods. This interprofessional MTM experience spanned three weeks, with health science students (medicine, nursing, nutrition, and pharmacy) meeting once weekly. The IPE facilitated interprofessional student collaboration via small-group sessions to conduct MTM consultations for patients with complex chronic conditions. Student learning and attitudinal changes were evaluated by comparing pre- and postIPE survey responses and a qualitative summary of the students' clinical recommendations. Efficacy of student groups was measured via patient satisfaction surveys and was reported by frequency of response. Results. Twenty-seven students participated in the program and 22 completed both pre- and post-IPE surveys ( $81 \%$ response rate). The survey included open-ended and Likert-type items assessing students' attitudes and skills regarding the IPE as well as their reactions to the experience. Significant changes were observed for two attitudinal items regarding interprofessional teams: maintaining enthusiasm/interest and responsiveness to patients' emotional and financial needs. Patient-reported satisfaction and students' complex clinical recommendations provided further evidence of student learning.

Conclusion. This novel IPE in MTM promoted interprofessional collaboration and education in this unique patient care area. Students' attitudes toward and skills in interprofessional collaboration improved, and the patients who received care reported positive experiences. Many health professions programs face challenges in meeting IPE requirements. The results of our study may provide the impetus for other institutions to develop similar programs to meet this urgent need.
\end{abstract}

Keywords: interprofessional education, interprofessional collaboration, medication therapy management, interprofessional rotations/experiences

\section{INTRODUCTION}

Interprofessional collaboration among health care providers is vital for the delivery of effective and safe patient-centered care. ${ }^{1,2}$ Integration of interprofessional education (IPE) into health professions curricula is well recognized and understood. ${ }^{2,3}$ Medication therapy management (MTM) services, now required as part of the Medicare Part D drug benefit, are designed to help beneficiaries with chronic conditions manage their medications. ${ }^{4}$ Assimilation of MTM services into advanced

Corresponding Author: Katherine E. Schussel, SinfoníaRx, 100 N. Stone Ave., Ste. 109, Tucson, AZ 85701. Tel. 520-9793711. E-mail: kschussel@sinfoniarx.com

Note: At the time of manuscript submission, Katherine E. Schussel was affiliated with the University of Arizona Medication Management Center in Tucson, AZ. pharmacy practice experiences (APPEs) can be successful; however, limited evidence exists regarding incorporation of MTM into an IPE for students. ${ }^{5}$ Medication therapy management services are typically delivered solely by pharmacists, limiting opportunities for integrating other healthcare professionals into this vital area of patient care. To address this, the University of Arizona Medication Management Center (UAMMC) identified a unique opportunity to teach interprofessional communication and team dynamics as part of its provision of MTM services for interprofessional students (medicine, nursing, nutrition, and pharmacy) in the final year of their degree programs.

The UAMMC is an innovative clinical call center primarily employing pharmacists, pharmacy technicians, pharmacy interns, and prepharmacy students in the 


\section{American Journal of Pharmaceutical Education 2019; 83 (3) Article 6584.}

delivery of MTM services to patients across the nation. Since its inception in 2006, the Center, which is located within the College of Pharmacy, has engaged pharmacy students, pharmacy residents, and hundreds of paid pharmacy interns. However, integrating other health sciences students in an IPE was a novel endeavor. The IPE program goals were to provide valuable interprofessional student learning experiences and to explore the roles of other professions in the provision of MTM while promoting interprofessionalism and comprehensive patient care at the UAMMC. The objective of this study was to implement an IPE in MTM and assess the impact of the experience on students' attitudes and skills about interprofessional collaboration.

\section{METHODS}

The student learning objectives (Table 1) for the IPE were adapted from the Interprofessional Education Collaborative (IPEC) Competencies. ${ }^{6}$ To address these objectives, participating students were offered multiple opportunities to work collaboratively with their interprofessional peers in the delivery of comprehensive, telephonic MTM services for patients with complex medical conditions. A unique feature of this IPE was conducting it over a three-week span, which allowed students to meet weekly three times rather than for just one day, which is typical for most IPE events or sessions. This extended schedule was developed intentionally to expand students' opportunities to engage with diverse patients and students from other professions; this schedule also helped prevent the scheduling challenges characteristic of clerkships and clinical advanced pharmacy practice experiences (APPEs).

Participating students were recruited using various methods. Fourth-year pharmacy students completing an APPE at the UAMMC were automatically included in the IPE experience. If additional openings for pharmacy students were available, participants were recruited from other nearby APPE sites. The College of Nursing included the IPE as one of their community health clinical site options for fourth-semester nursing students, Nursing faculty members selected respective students based on areas of interest that students had indicated on a rotation placement survey. College of Medicine students participated on a voluntary basis. The IPE was advertised by a medical student organization that tracked students' involvement in cocurricular volunteer programs and awarded them with a special distinction on their transcript. Finally, fourth-year students from the College of Nutritional Sciences who were interested in pursuing a dietetic internship were identified by faculty members and offered independent study credit for their participation in the IPE.

Only students in the final year of their degree program were invited to participate in the IPE; the goal was to ensure that all students possessed similar levels of the skills and experience needed to make clinical interventions for patients with complex conditions. None of the didactic curricula completed by health sciences students

Table 1. Learning Objectives and Associated Student Pre-Post Survey Statements Mapped for an Interprofessional Education Experience in Medication Therapy Management

\section{Learning Objective}

Associated Student Pre-Post Survey Statement Numbers (\#)

Describe the unique roles, responsibilities, and expertise of other health professions in the delivery of MTM services.

Demonstrate an ability to work in cooperation with patients, providers, and others involved in the delivery of prevention and health services.

Engage diverse health care professionals and their associated resources to develop strategies to meet specific patient care needs.

Demonstrate the full scope of knowledge, skills, and abilities required from available health professionals and health care workers to provide safe, timely, efficient, effective, and equitable care.

Demonstrate active listening skills to encourage ideas and opinions of other team members.

Express one's knowledge and opinions to team members involved in patient care with confidence, clarity, and respect, working to ensure common understanding of information and treatment and care decisions.

Apply leadership practices that support collaborative practice and team effectiveness.

$1,4,10$

$2,3,8,9,17$

$1,2,3,10,11,13,15,17$

$1,2,3,4,12,13,15,16,18$

$2,5,19,20$

$1,5,6,19,20$

$2,3,4,7,8,9,11,14,17$ 


\section{American Journal of Pharmaceutical Education 2019; 83 (3) Article 6584.}

formally included MTM experiences. However, pharmacy students may have been introduced to related concepts; had introductory pharmacy practice experiences within the MTM field; or worked at the UAMMC prior to enrolling in the IPE. Other conditions, considered by Allport's Contact Hypothesis as necessary to reduce intergroup conflict and promote a positive attitudinal change, were integrated into the development of this experience. ${ }^{7}$ For example, it was important for the developers to ensure that each group had equal status in the contact situation (ie, involvement in the IPE); there was a cooperative atmosphere; individuals were working on common goals; there was institutional support for the IPE; students were aware of the similarities and differences in their roles; students had positive experiences during the IPE; and participants perceived each other as typical members of their group (ie, typical representatives of health professional students).

Throughout the experience, two pharmacy and two nursing students met with either two medicine or two nutritional science students, forming an IPE student team of six students per rotation. The instructors, a registered nurse and pharmacist employed by the UAMMC, modeled real-world interprofessional care and supervised students' activities and patient interactions. Each morning, the six IPE students worked through complex case studies as a team, with guidance from the pharmacist and nurse preceptors. The purpose was to familiarize students with the MTM consultation process and to practice teamwork and communication strategies. The group then presented their case study findings to the preceptors and simulated a consultation with one of the preceptors role-playing as the patient. Following the mock phone call to the patient, students were debriefed to: identify strategies to work more collaboratively; discuss strengths of their clinical recommendations and patient counseling; and clarify any points of confusion about the process with the preceptors. Throughout the case study process, the preceptors provided constructive feedback regarding student teamwork, patient counseling skills, and clinical recommendations.

To facilitate knowledge and skill acquisition for conducting actual MTM patient consultations, the six students spent roughly two hours completing two or three case studies as a group. Students then were divided into two teams of three students, with one student per profession on each team. The two teams spent the remaining five hours of the IPE day preparing for and calling actual patients. To facilitate students' preparation, patients received a telephone call two to three days in advance to request their participation in a consultation conducted by students as part of an IPE. The patient population available for MTM consultations at any point in time depended on the UAMMC's current health plan contracts. Patients involved in the IPE consultations included those who had recently been discharged from the hospital (via a collaborative program with a local hospital) and Medicare beneficiaries enrolled in their health plan's MTM program.

In preparation for the scheduled telephone calls with actual patients, students were asked to focus on their profession's unique areas of expertise in the following: developing potential patient-related questions and counseling points (learning outcome 1); sharing ideas and clinical recommendations with their interprofessional teammates (learning outcomes 5 and 6); and developing a comprehensive consultation plan (learning outcomes 2, 3 , and 4). They also used patient records (eg, hospital electronic health records or medication claims data) for each MTM review.

For the actual consultation, students followed a structured clinical call script, which the site preceptors had developed to guide this process. The script included counseling discussion points for the respective professions to address with the patient as appropriate. Immediately prior to the MTM review with the patient, students presented the patient case as a group to the pharmacist and nurse preceptors. Each student included the profession-specific description of the information that he or she intended to address with the patient. The preceptors provided student feedback regarding their clinical recommendations and respective responsibilities within the team.

During the MTM review with the patient, students followed the clinical call script; however, they were given latitude to adapt and customize their counseling and recommendations based on pertinent concerns identified during the conversation with the patient (learning outcomes 7). All three of the students on each MTM team spoke to the patient. First, the nursing student initiated the call, completed the medication reconciliation, updated the information about the patient's allergies, and discussed nursing-related counseling points. Next, the pharmacy student discussed medication-related concerns and recommendations with the patient. Finally, the medicine or dietetics student closed the call with questions and counseling points specific to their profession. To ensure the accuracy and appropriateness of the information relayed to the patient, the nurse and pharmacist preceptors listened in on the call. The preceptors were also available to assist students if they encountered a situation where they felt ill-equipped to address the patient's concerns on their own. Each team typically completed two to four MTM consultations per day as time and patient availability allowed. 


\section{American Journal of Pharmaceutical Education 2019; 83 (3) Article 6584.}

After each phone call, students debriefed with their team members and preceptors. This group discussion provided a valuable opportunity for the preceptors to offer constructive feedback regarding clinical and team collaboration skills; it also allowed self-reflection regarding their group participation and patient interactions (learning outcomes 5 and 6 ). Next, the students developed a progress note for the patient records that included: assessment of the patient's medication regimen and overall health status, important patient follow-up instructions, information to relay to the patient's providers, and the students' recommendations. Students also identified important patient reminders and information for inclusion in the medication action plan (MAP). The MAP and an updated medication list were part of the comprehensive medication review (CMR), which was mailed to the patient in a follow-up letter.

Outcomes were classified according to the Kirkpatrick/Freeth model (Table 2) which distinguishes four levels of learning (Level 1: Reaction; Level 2a: Modification of attitudes/perceptions; Level 2b: Acquisition of knowledge/skills; Level 3: Behavioral change; Level 4a: Changes in organizational practice; and Level $4 \mathrm{~b}$ :
Benefits to patients/clients). ${ }^{8}$ The post-IPE survey contained open-ended questions to capture students' reactions to the program and gain insight into their perceptions regarding their experience (Level 1: Reaction). The questions included: What did you like BEST about this interprofessional experience? How did you feel about working on patient cases in an interprofessional group? Was it easier or harder than you anticipated? Did you learn anything in particular about working with other healthcare professionals? What did you like LEAST about this interprofessional experience? and Do you have any comments or suggestions to improve the experience for future students?

To evaluate student IPC attitudes and skills (Levels 2a and $2 \mathrm{~b}$ ) and determine their progress in meeting the experience learning objectives for the IPE, the student survey for the IPE contained Likert scale items. The pre- and postsurvey instruments were almost identical, with the exception of the open-ended program evaluation questions added to the post-IPE survey. The survey items (Table 3) were developed from the Interprofessional Education Collaborative (IEC) Core Competencies based on their four core domains: values and ethics for interprofessional practice,

Table 2. Outcomes from an Interprofessional Education Experience in Medication Therapy Management According to the Kirkpatrick/Freeth Model $^{7}$

\begin{tabular}{|c|c|c|c|c|}
\hline $\begin{array}{l}\text { Kirkpatrick/Freeth } \\
\text { Model Level }\end{array}$ & Definition & Measurement Tool & Subjects & Focus of Outcome \\
\hline 1: Reaction & $\begin{array}{l}\text { Learners' views on the learning } \\
\text { experience and its } \\
\text { interprofessional nature }\end{array}$ & $\begin{array}{l}\text { Open-ended questions on } \\
\text { post-IPE student survey }\end{array}$ & Students & $\begin{array}{l}\text { Student attitude toward } \\
\text { IPE }\end{array}$ \\
\hline $\begin{array}{l}\text { 2a: Modification of } \\
\text { attitudes/perceptions }\end{array}$ & $\begin{array}{l}\text { Changes in reciprocal attitudes } \\
\text { or perceptions between } \\
\text { participant groups. Changes in } \\
\text { perception or attitude towards } \\
\text { the value and/or use of team } \\
\text { approaches to caring for a } \\
\text { specific client group }\end{array}$ & $\begin{array}{l}\text { Scaled questions on pre- and } \\
\text { post-IPE student survey }\end{array}$ & Students & $\begin{array}{l}\text { Program Evaluation } \\
\text { Student attitude toward } \\
\text { IPC }\end{array}$ \\
\hline $\begin{array}{l}\text { 2b: Acquisition of } \\
\text { knowledge/skills }\end{array}$ & $\begin{array}{l}\text { Including knowledge and skills } \\
\text { linked to interprofessional } \\
\text { collaboration }\end{array}$ & Clinical recommendations & Students & $\begin{array}{l}\text { Student knowledge and } \\
\text { skills }\end{array}$ \\
\hline & $\begin{array}{l}\text { their practice setting and } \\
\text { changed professional practice. }\end{array}$ & Patient Satisfaction Survey & Patients & $\begin{array}{r}\text { Student behavior } \\
\text { toward patient }\end{array}$ \\
\hline $\begin{array}{l}\text { 4a: Changes in } \\
\text { organizational practice }\end{array}$ & $\begin{array}{l}\text { Wider changes in the } \\
\text { organization and delivery of } \\
\text { care }\end{array}$ & $\begin{array}{l}\text { Informal evaluation of } \\
\text { interprofession- alism at the } \\
\text { UAMMC }\end{array}$ & Site & $\begin{array}{l}\text { Increase in } \\
\text { Interprofessional } \\
\text { collaboration at site }\end{array}$ \\
\hline $\begin{array}{l}\text { 4b: Benefits to patients/ } \\
\text { clients }\end{array}$ & $\begin{array}{l}\text { Improvements in health or well- } \\
\text { being of patients/clients }\end{array}$ & Patient Satisfaction Survey & Patient & Impact on patient \\
\hline
\end{tabular}

Abbreviations: IPE = Interprofessional Education, IPC = Interprofessional Collaboration, UAMMC=University of Arizona Medication Management Center 
American Journal of Pharmaceutical Education 2019; 83 (3) Article 6584.

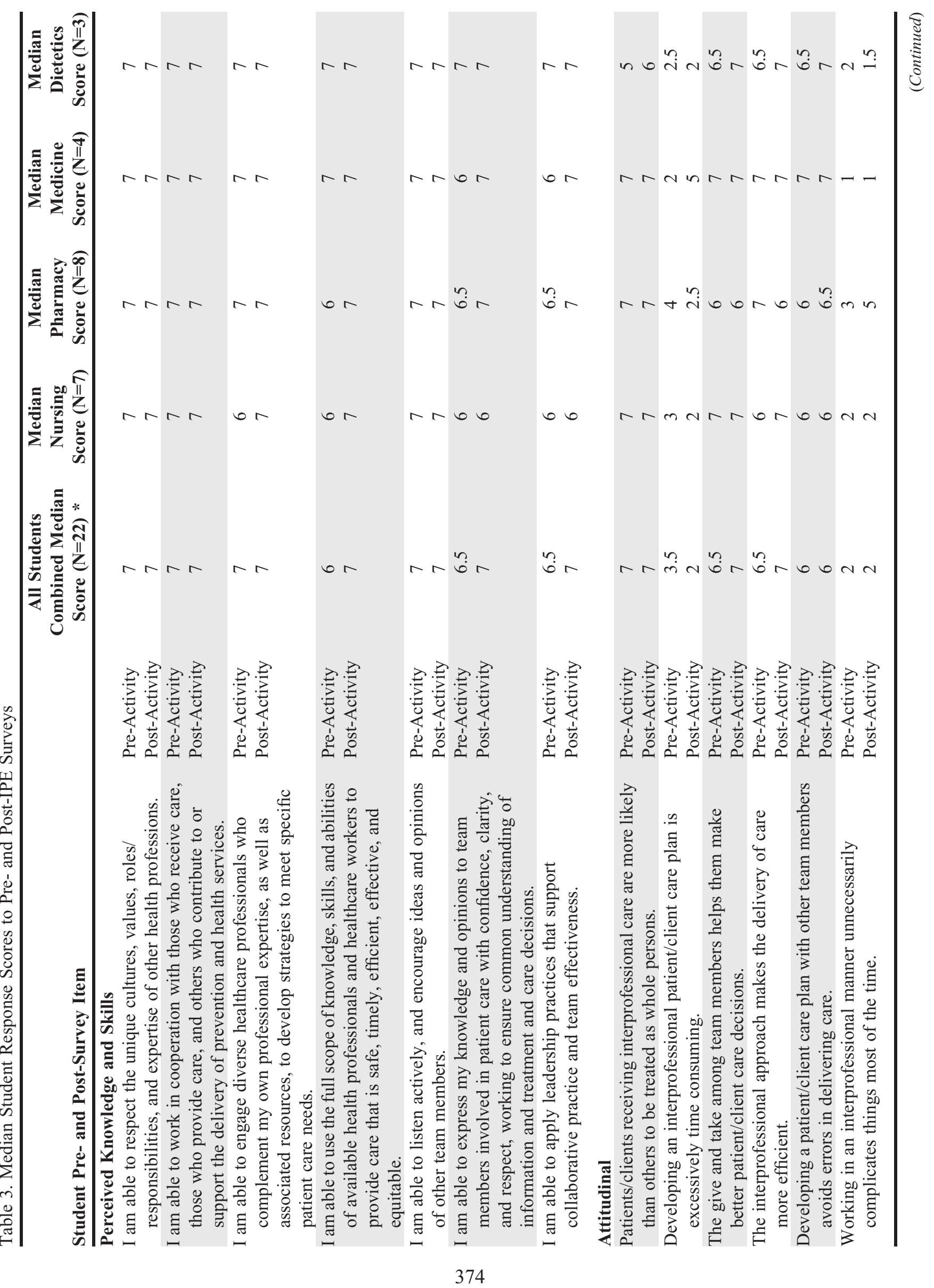


American Journal of Pharmaceutical Education 2019; 83 (3) Article 6584.

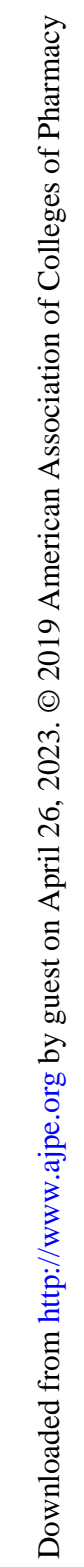

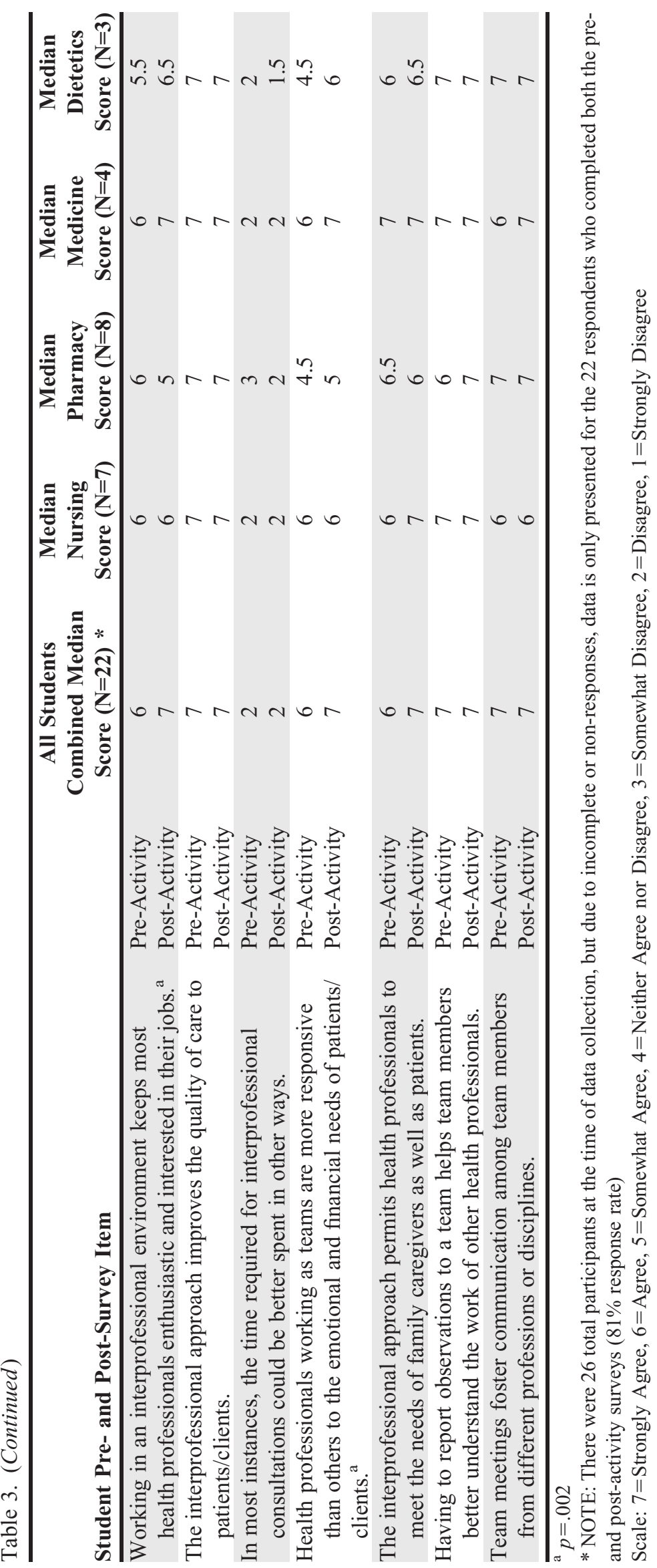




\section{American Journal of Pharmaceutical Education 2019; 83 (3) Article 6584.}

roles and responsibilities, interprofessional communication, and teams and teamwork. ${ }^{6}$ Similarly, Dow and colleagues adapted the IPEC competencies to define IPE program success via the Interprofessional Education Collaborative (IPEC) Competency Survey. ${ }^{9}$ Dow's findings suggest that it is feasible to use a questionnaire based on IPEC competencies. ${ }^{9}$ A 7 -item Likert scale ranging from 1-7 was used for item responses: $7=$ strongly agree; $6=$ agree; $5=$ somewhat agree; $4=$ neither agree nor disagree; $3=$ somewhat disagree; $2=$ disagree; and $1=$ strongly disagree.

During the first two full rotations of the IPE, another project was ongoing at the UAMMC that allowed for coincidental documentation of recommendations and interventions to illustrate the clinical impact of the students' consultations. This information was used to document and evaluate the student groups' application of clinical MTM-related knowledge and IPC skills (Levels $2 \mathrm{~b}$ and 3 ). This ongoing project also allowed for collection of information about patient satisfaction during the first two IPE rotations; the patient satisfaction survey was administered by a neutral party in a separate telephone call within three months of the consultation. Patients were asked to respond to 17 statements regarding their experience with the student group consultation using a 4-item Likert scale. The statements were classified into four distinct categories: medication knowledge, self-management/empowerment, addressing concerns, and patient experience. The purpose was to measure patients' satisfaction with the program related to receiving care from an interprofessional student team (Level $4 \mathrm{~b}$ ) and student behavior toward patients (Level 3).

The UAMMC's organizational environment and interprofessional collaboration were observed informally by the center's nurse manager/IPE coordinator to assess interprofessionalism before and after implementation of the IPE (Level 4a).

A mixed-method approach was used for the analyses. The student pre-and post-IPE survey was administered via email on Qualtrics (Provo, UT). Students were emailed an IPE survey link one week before the rotation and again one day after the last session. Responses to the open-ended questions were qualitatively reviewed by the authors for recurrent themes or concepts. Once themes were identified, the data were reevaluated to determine the number of responses that addressed the most commonly occurring themes. The pre- and post-survey responses to the Likert-scale items were compared using a Wilcoxon signed rank test. The student groups' recommendations and clinical interventions for patients were collected and categorized. Finally, data from patient satisfaction surveys were summarized and reported as frequencies.

\section{RESULTS}

Twenty-seven students participated in the IPE over four offerings. Of these, 22 students completed both the pre- and post-IPE student surveys ( $81 \%$ response rate); five students' responses were excluded from the analyses because of incomplete responses. The survey results are presented in Table 3.

Several recurrent themes were identified in the openended responses on the postsurvey (see Appendix A for specific student comments). Eight students (36\%) found that integration of other professions allowed them to learn a considerable amount of clinical information from their colleagues and helped them better understand the expertise and roles of other professions on the health care team. One-fourth of respondents (27\%) indicated that the interprofessional experience was easier than they originally anticipated, primarily due to the cooperation and support of the other students. In other words, these students believed that team collaboration improved patient interaction and the overall student experience. Four participants $(18 \%)$ expressed that they enjoyed working with actual patients rather than only preparing case studies as they had done in other IPE activities. Four of the students (18\%) also mentioned that incorporating videotaped examples of MTM calls into the IPE curriculum materials would improve their experience and better prepare them for conducting the live calls with patients. All of the students' responses on the post-survey support Level 1 (reaction) of the Kirkpatrick/Freeth model (Table 2)

Results of the Wilcoxon signed rank test showed a significant positive difference between two of the attitudinal survey items. The items included "Working in an interprofessional environment keeps most health professionals enthusiastic and interested in their jobs" $(p=.002)$ and "Health professionals working as teams are more responsive than others to the emotional and financial needs of patients/clients" $(p=.002)$. These responses support Level 2a: Modification of attitudes/perceptions (Table 2). Students' responses to the other 18 items remained the same or were only slightly improved from pre- to postsurvey. The pre- and post-IPE student survey results from all four rotations are presented in Table 3. These student reactions support Level 2a (modification of attitudes/perceptions) of the Kirkpatrick/Freeth model (Table 2).

A wide variety of clinically significant and complex concerns were identified during the student-patient consultations. Students acted on medication-related safety problems and gaps in adherence to national treatment guidelines. This demonstrates the clinical aspect of the 


\section{American Journal of Pharmaceutical Education 2019; 83 (3) Article 6584.}

students' learning during the IPC experience, which was a significant addition to the interprofessional collaboration skills that they gained. These findings supports Level $2 \mathrm{~b}$ (acquisition of knowledge/skills) of the Kirkpatrick/ Freeth model (Table 2).

Students' behavior was evaluated via the clinical recommendations described above. The interventions illustrated the students' ability to work as a cohesive team to identify pertinent safety concerns and patient education needs. Positive responses collected during the patient satisfaction survey (Table 4) indicated the student teams' success in delivering their interprofessional MTM services from a patient's perspective. For example, all six (100\%) patients who received a consultation from an interprofessional student team and responded to the survey indicated they strongly agreed that they were satisfied with the overall care provided and that the students were respectful during their interactions. Additionally, all of the respondents strongly agreed or agreed that the students helped them to better understand why they were taking their medications. These results support Level 3 (Behavioral change) of the Kirkpatrick/Freeth model (Table 2).

Since the inception of the IPE at the UAMMC, the organization has expanded the roles of other professions in the delivery of MTM services to patients across the nation. Prior to launching the IPE, the UAMMC staff was composed almost exclusively of pharmacists, pharmacy interns, and pharmacy technicians. In the year following implementation of the IPE, the UAMMC hired a team of nursing students to provide MTM counseling services. The Center also initiated dietetics related educational sessions for staff to increase their knowledge and facilitate integration of nutrition-related information into their MTM patient counseling. These results support Level $4 \mathrm{a}$ (changes in organizational practice) of the Kirkpatrick/Freeth model (Table 2).

The positive results from the patient satisfaction survey illustrate the benefits of the interprofessional MTM consultations. All patients (6 [100\%]) surveyed strongly agreed or agreed with the statements in the domain of medication knowledge (eg, "The students helped me understand the best ways to take my medicines"). Additionally, all respondents strongly agreed or agreed that the student-made recommendations for the patient's overall health and the MTM service would improve their health. These results support level $4 \mathrm{~b}$ (benefits to patients/clients) of the Kirkpatrick/Freeth model (Table 2). The patient satisfaction survey results are presented in Table 4.

\section{DISCUSSION}

The UAMMC's comprehensive approach to MTM, combined with the paucity of published reports on IPE activities involving these services, prompted development of this interprofessional collaboration experience. The UAMMC has a strong history of engaging student pharmacists in the delivery of MTM services to their patients. Furthermore, the Center is an APPE site for pharmacy students, thus systems were already in place to allow for flexibility in scheduling and to accommodate students from other health sciences colleges. All of these factors facilitated the introduction of a longer IPE program that spanned a three-week period and integrated the delivery of MTM services. This IPE program paralleled similar work by Mann and colleagues in that it focused on the learner's experience while creating an opportunity for students to participate in the health care system. ${ }^{10}$ The IPE is the first program of its type at the Univeristy of Arizona College of Pharmacy and, to our knowledge, at any college of pharmacy across the nation. The unique schedule of this IPE experience, held one full day per week for three weeks, enabled participation by other health sciences students. The rotational nature of the IPE provided several options for colleges to incorporate the activities to best fit their students' schedules and curricula (ie, incorporate the IPE into their existing clinical rotations, offer the IPE as a volunteer experience, or offer the IPE as an independent study). We believe this flexibility resulted in full-capacity student participation in each of the four offerings of the IPE assessed in this study. Additionally, the experiential component gave interprofessional student teams the option to interact within the healthcare system and with actual patients.

Overall, the students involved in the IPE described improvements in their interprofessional skills, delivered interprofessional MTM consultations at a high level as reflected by patient satisfaction ratings, and practiced making sound clinical judgements. Based on the Kirkpatrick/Freeth model, positive changes were observed in students' reaction (ie, attitudes toward the experience), behavior, knowledge regarding IPC and MTM, and clinical outcomes for their patients. ${ }^{8}$ Specifically, the students: indicated improvement in self-reported views of IPC between the pre- and post-IPE student surveys (Levels 1 and 2a), demonstrated effective delivery of MTM consultations with high patient-reported satisfaction (Levels 3 and 4b), and provided appropriate, robust group-generated clinical interventions to their patients (Levels $2 b$ and 3 ).

As noted above and in Table 1, the pre- and post-IPE student survey results showed that the IPE activities successfully addressed our learning objectives. Additionally, these results revealed that interprofessional education integrating MTM as the clinical experience is a viable option. Students' numerous interventions and recommendations 
American Journal of Pharmaceutical Education 2019; 83 (3) Article 6584.

Table 4. Patient-Reported Satisfaction with Interprofessional Student Group Medication Therapy Management Consultation

\begin{tabular}{|c|c|c|c|c|c|c|}
\hline \multirow[b]{2}{*}{ Domain } & \multirow[b]{2}{*}{ Question } & \multicolumn{5}{|c|}{ Patient Satisfaction Response Frequencies n (\%) $(n=6)$} \\
\hline & & $\begin{array}{l}\text { Strongly } \\
\text { Agree }\end{array}$ & Agree & Disagree & $\begin{array}{l}\text { Strongly } \\
\text { Disagree }\end{array}$ & $\begin{array}{c}\text { Not } \\
\text { Applicable }\end{array}$ \\
\hline \multirow[t]{4}{*}{$\begin{array}{l}\text { Medication } \\
\text { Knowledge }\end{array}$} & $\begin{array}{l}\text { The students made sure I understood following } \\
\text { the drug regimen. }\end{array}$ & $5(83.3)$ & $1(16.7)$ & 0 & 0 & 0 \\
\hline & $\begin{array}{l}\text { The students helped me to understand why } \\
\text { I am taking each of my medicines. }\end{array}$ & $4(66.7)$ & $2(33.3)$ & 0 & 0 & 0 \\
\hline & $\begin{array}{l}\text { The students helped me understand how to } \\
\text { know if my medicines are working. }\end{array}$ & $4(66.7)$ & $2(33.3)$ & 0 & 0 & 0 \\
\hline & $\begin{array}{l}\text { The students helped me understand the best } \\
\text { ways to take my medicines. }\end{array}$ & $5(83.3)$ & $1(16.7)$ & 0 & 0 & 0 \\
\hline \multirow[t]{4}{*}{$\begin{array}{r}\text { Self-management/ } \\
\text { Empowerment }\end{array}$} & $\begin{array}{l}\text { After talking with the students, I feel more } \\
\text { confident to manage my medicines. }\end{array}$ & $5(83.3)$ & $1(16.7)$ & 0 & 0 & 0 \\
\hline & $\begin{array}{l}\text { The students encouraged me to achieve my } \\
\text { treatment goals. }\end{array}$ & $4(66.7)$ & $1(16.7)$ & 0 & 0 & $1(16.7)$ \\
\hline & $\begin{array}{l}\text { The students made recommendations for my } \\
\text { overall health. }\end{array}$ & $5(83.3)$ & $1(16.7)$ & 0 & 0 & 0 \\
\hline & $\begin{array}{l}\text { The students helped me find easier ways } \\
\text { to take my medicines. }\end{array}$ & $4(66.7)$ & 0 & $1(16.7)$ & 0 & $1(16.7)$ \\
\hline \multirow[t]{4}{*}{$\begin{array}{l}\text { Addressing } \\
\text { Concerns }\end{array}$} & $\begin{array}{l}\text { The students listened to concerns about my } \\
\text { medicines. }\end{array}$ & $6(100)$ & 0 & 0 & 0 & 0 \\
\hline & The students addressed my health concerns. & $5(83.3)$ & $1(16.7)$ & 0 & 0 & 0 \\
\hline & $\begin{array}{l}\text { The students addressed my concerns about } \\
\text { the safety of medicines. }\end{array}$ & $5(83.3)$ & $1(16.7)$ & 0 & 0 & 0 \\
\hline & $\begin{array}{l}\text { The students addressed my concerns about } \\
\text { the cost of my health care. }\end{array}$ & $3(50)$ & 0 & $1(16.7)$ & 0 & $2(33.3)$ \\
\hline \multirow[t]{5}{*}{$\begin{array}{l}\text { Patient } \\
\text { Experience }\end{array}$} & $\begin{array}{l}\text { I was satisfied with the students for overall } \\
\text { care provided. }\end{array}$ & $6(100)$ & 0 & 0 & 0 & 0 \\
\hline & $\begin{array}{l}\text { The students were respectful during our } \\
\text { interactions. }\end{array}$ & $6(100)$ & 0 & 0 & 0 & 0 \\
\hline & $\begin{array}{l}\text { Due to my experience with this type of care, } \\
\text { I would recommend it. }\end{array}$ & $5(83.3)$ & $1(16.7)$ & 0 & 0 & 0 \\
\hline & I value the information the students gave me. & $5(83.3)$ & $1(16.7)$ & 0 & 0 & 0 \\
\hline & I feel this service will improve my health. & $4(66.7)$ & $2(33.3)$ & 0 & 0 & 0 \\
\hline
\end{tabular}

had a significant impact on patient safety and care. Patientreported satisfaction with the interprofessional experience was positive, illustrating the success of using students and interprofessional teams in the delivery of these services. Kostas and colleagues also found that educating clinical trainees in management of medications for elderly patients resulted in the trainees having improved ability to perform accurate medication reviews and experiencing selfreported behavioral changes. ${ }^{11}$ Together, these successes provide initial evidence that interprofessional medication management training is valuable. More specifically, our findings show that the IPE at the UAMMC is an effective student learning experience.

In addition to students' reactions to the program and opportunities for programmatic improvement, the openended responses to the post-IPE student survey also shed light on future student behavioral changes (Level 3). For example, responses such as, "In the future, I know what I can ask them [pharmacists and dieticians] in regards to patient health" indicate that students may alter their professional practice toward a more collaborative approach as a result of participating in the IPE program. Furthermore, comments such as, "After the experience, I value interprofessional collaboration because it truly benefits the client [patient]" suggest that these potential shifts in thought processes may also have an impact on future patient interactions, which align with the ultimate goal of IPE which is to improve patient care.

Additionally, this IPE provided the impetus for UAMMC to explore the potential for interprofessionalism within MTM by integrating various health science student groups into this once pharmacy-dominated space. The UAMMC nurse manager/IPE coordinator and pharmacist preceptors' roles provided initial support for IPC at 


\section{American Journal of Pharmaceutical Education 2019; 83 (3) Article 6584.}

UAMMC and in the MTM field in general. However, prior to initiation of the IPE experience, little was known about the impact of integrating other professions on a larger scale at the direct patient care level. After implementing these rotations, UAMMC personnel were able to fully comprehend the goal of interprofessional, comprehensive patient care. As a result, the UAMMC hired a team of student nurses, complementing the large, already established team of student pharmacists. Integration of dietetics in-services for the UAMMC clinical staff illustrate another potential benefit and relationships that resulted from the collaborative process of developing the IPE; in this case, it resulted in subsequent realization of the important role dietitians play in the delivery of MTM consultations. This innovative IPE is at the forefront of the newly discovered interprofessional MTM environment as a result of highlighting the important roles of other healthcare professions, demonstrating their feasibility, and promoting the benefits of their integration into MTM services.

To implement a similar IPE workflow within other settings, such as health sciences colleges and community pharmacies, many of the UAMMC IPE components are replicable. However, replication is dependent on having dedicated personnel and the infrastructure in place to implement the program. A requisite component for the development of a similar IPE program is establishing relationships with respective health sciences colleges. The most significant barrier to IPE program implementation is most often related to scheduling. Thus, working with the other colleges to ensure the IPE schedule (days/ times) is realistic and facilitates student participation is critical. For example, the flexible schedule (ie, once weekly for a three-week period) of the IPE allowed colleges and their respective students to participate more readily. The required resources for implementing this IPE included: a database of MTM-eligible patients, desktop computers for student use, a conference call-enabled telephone system, a small classroom or conference room, and an LCD projector. Additionally, designated personnel are needed to coordinate and implement the IPE program. In the UAMMC, the nurse and pharmacist preceptors guided and assisted the students at all times during each IPE session, which required a significant investment of personnel resources. Prior to each rotation, the nurse coordinator also spent several hours scheduling students, developing materials, and organizing resources. Additional resources were required from the UAMMC clinical support staff (ie, pharmacy technicians) for scheduling the patient consultations. Scaling the IPE would require having enough preceptors to direct the students through the process, a larger workspace for the student groups, computers to access the database, complete IPE requirements (ie, assignments, patient consultations), and sufficient patients to participate in the MTM consultations.

Physical space and preceptor availability limit the IPE program's capacity to the current number of students (six per day). The interprofessional education model within Arizona University allows students to complete the required and elective components. While this program only has the capacity to remain an elective (rather than a required) component of the UACOP curriculum, it has become a model for other experiences within the health sciences schools at this university. We plan to continue exploring innovative models for incorporating IPE into experiential learning rather than trying to offer the program to all students, which is unrealistic at this time.

There were several limitations to this study. The timing of survey administration may have affected the results and increased the potential for response-shift bias. ${ }^{12} \mathrm{Ad}-$ ministering separate pre- and post-IPE student surveys may have inadvertently affected participants' perceptions of their initial knowledge, attitudes, and behavior, and thereby increased the potential for artificially inflating these results. For example, students may have initially rated themselves high in their ability to work as a team. However, after completing the IPE, they may have realized their teamwork skills were not as strong as they originally thought. Indeed, most students rated their interprofessional skills very highly in the pre-IPE survey. To address this challenge with future students, the preceptors will administer a retrospective pre-post student survey following completion of the IPE to help prevent response-shift bias. Additionally, the pre- and post-IPE student survey was not validated before using it in this study and will need to be psychometrically validated for future application. Furthermore, only two of the 20 survey items showed significant student improvement from pre- to post-IPE. Thus, the small sample may have been insufficient to detect significant improvement on other items. The very small numbers of students and patients involved with the IPE in this study significantly limits the generalizability of our findings. Finally, given the newness of this program, administering follow-up surveys to previous participants to determine longer-term learning or behavior changes is not possible yet. While the overall intent for this experience was to instill students with a better understanding and appreciation for MTM services, measuring the impact of this IPE program on students' future interactions with healthcare providers may be difficult. Future plans include validation of the pre- and post-IPE student survey items and development and administration of follow-up surveys to assess longer-term learning, behavioral changes, and 


\section{American Journal of Pharmaceutical Education 2019; 83 (3) Article 6584.}

MTM acceptance rates in program participants after graduation.

\section{CONCLUSION}

This IPE in MTM provided a novel approach to promote interprofessional collaboration and education in this unique area of patient care. The program improved students' attitudes toward and skills in interprofessional collaboration while contributing to improved interprofessionalism at the UAMMC and within the MTM services provided to patients. These results are encouraging; however, additional research with larger student populations and in more diverse settings is warranted. In summary, while many colleges of health professions face challenges meeting the IPE requirements outlined in accreditation standards, this IPE program may serve as a model for other institutions to develop similar programs to help them meet these urgent provisions. ${ }^{13}$

\section{ACKNOWLEDGMENTS}

The authors thank the large team of supporters that helped develop and maintain this program. In particular, we thank Rose Martin, PharmD, for her inspiration and vision in starting this program while serving as director of the Medication Management Center. We also thank the preceptors who helped implement the rotation, including Nicole Scovis, PharmD; Robert Lipsy, PharmD; Jessica Dileo, PharmD; and Whitney Shields, PharmD. Additionally, this project would not be possible without our interprofessional faculty champions: Mary Marian, DCN, in the Department of Nutritional Sciences; Hildi M. Williams in the College of Medicine; and Patricia Goldsmith, MS, RN, in the College of Nursing.

\section{REFERENCES}

1. World Health Organization. Framework for Action on Interprofessional Education and Collaborative Practice. http://www. who.int/hrh/resources/framework_action/en/. Published 2010. Accessed March 27, 2019.

2. Page RL, Hume AL, Trujillo JM, et al. Interprofessional education: principles and application. A framework for clinical pharmacy. Pharmacotherapy. 2009;29(3):145e-164e. doi: 10.1002/ jac5.1025.

3. Institute of Medicine. Health Professions Education: A Bridge to Quality. Washington, DC: The National Academies Press. Published 2003. https://doi.org/10.17226/10681.

4. U.S. Government Publishing Office. Public Law 108-173 Medicare Prescription Drug, Improvement, and Modernization Act of 2003. https://www.gpo.gov/fdsys/pkg/PLAW-108publ173/ content-detail.html. Approved December 8, 2003. Accessed March 27, 2019.

5. Nuffer W, Gilliam E, Thompson M, Vande Griend J. Establishment and implementation of a required medication therapy management advanced pharmacy practice experience. Am J Pharm Educ. 2017;81(2):36.

6. Interprofessional Education Collaborative. Core competencies for interprofessional collaborative practice: 2016 update. Washington, DC: Interprofessional Education Collaborative. https://nebula. wsimg.com/2f68a39520b03336b41038c370497473?

AccessKeyId $=$ DC06780E69ED19E2B3A5\&disposition $=0$

\&alloworigin=1. Published 2016. Accessed March 27, 2019.

7. Hean S, Dickinson C. The contact hypothesis: an exploration of its further potential in interprofessional education. $J$ Interprof Care. 2005;19(5):480-491.

8. Freeth D, Hammick M, Koppel I, Reeves S, Barr H. A critical review of evaluations of interprofessional education: occasional paper no. 2. London, UK: Learning and Teaching Support Network (LTSN) Health Sciences and Practice from the Interprofessional Education Joint Evaluation Team. May 2002. Accessed March 27, 2019.

9. Dow AW, Diazgranados D, Mazmanian PE, Retchin SM. An exploratory study of an assessment tool derived from the competencies of the interprofessional education collaborative. $J$ Interprof Care. 2014;28(4):299-304.

10. Mann KV, Mcfetridge-Durdle J, Martin-Misener R, et al. Interprofessional education for students of the health professions: the "Seamless Care" model. J Interprof Care. 2009;23(3):224-233. 11. Kostas T, Zimmerman K, Salow M, et al. Improving medication management competency of clinical trainees in geriatrics. $J \mathrm{Am}$ Geriatr Soc. 2014;62(8):1568-1574.

12. Howard G. Response-shift bias: A problem in evaluating interventions with pre/post self-reports. Eval Rev. 1980;4(1):93-106. Accessed March 27, 2019.

13. Accreditation Council of Pharmacy Education. Accreditation standards and key elements for the professional program leading to the doctor of pharmacy degree (Standards 2016). https://www.acpeaccredit.org/pdf/Standards2016FINAL.pdf. Accessed March 27, 2019. 


\section{American Journal of Pharmaceutical Education 2019; 83 (3) Article 6584.}

Appendix 1. Sample Post-IPE Survey Open-Ended Student Comments

\begin{tabular}{|c|c|}
\hline Theme & Student Comments \\
\hline $\begin{array}{l}\text { Felt that the interprofessional experience was easier than they } \\
\text { were originally anticipated due to the support of the other } \\
\text { students and their cooperation }(n=6)\end{array}$ & $\begin{array}{l}\text { "I liked working on patient cases with the other students. It was } \\
\text { definitely easier than I anticipated since everyone else was } \\
\text { very cooperative and willing to work together." } \\
\text { "It was much easier to complete the task with the support of the } \\
\text { other professional students; each student contributed a unique } \\
\text { energy and understanding. I was initially concerned that I } \\
\text { would feel very behind in this exercise. I was concerned that I } \\
\text { would not be able to adequately contribute to medication } \\
\text { management care compared to the pharmacy student. } \\
\text { However, I feel that each member of the team contributed in a } \\
\text { unique and complementary manner." }\end{array}$ \\
\hline $\begin{array}{l}\text { Enjoyed working with live patients, as opposed to working only } \\
\text { with case studies in other IPE activities }(n=4) \text {. }\end{array}$ & $\begin{array}{l}\text { "I appreciated and valued everyone's expertise and background } \\
\text { and felt we were able to contribute to a REAL situation." } \\
\text { "All my other interprofessional experiences were all mock } \\
\text { experiences so I enjoyed being able to work with real } \\
\text { patients." }\end{array}$ \\
\hline $\begin{array}{l}\text { Felt that incorporating examples of MTM calls into the } \\
\text { curriculum materials would improve their experience and } \\
\text { better prepare them for conducting the live calls with patients } \\
(n=4) .\end{array}$ & $\begin{array}{l}\text { "Provide a good example/demo of an ideal follow-up phone call } \\
\text { so that we have a better of idea of what to model after. } \\
\text { Otherwise, I think this is great project and I hope that it is } \\
\text { successful." }\end{array}$ \\
\hline
\end{tabular}

